\title{
Polyester Fleeces used as an Artificial Interstitium Influence the Spatial Growth of Regenerating Tubules
}

\section{Anne Glashauser, Lucia Denk and Will W. Minuth*}

Molecular and Cellular Anatomy, University of Regensburg, University Street 31, D-93053 Regensburg, Germany

\begin{abstract}
In regenerative medicine the use of stem/progenitor cells is a valuable therapeutical option for the regeneration of diseased tissues and organs. However, the secure application of cell-based therapies for the treatment of renal failure requires exact information regarding the mechanisms of parenchyma development in combination with different kinds of biomaterials.

Recently, we demonstrated that application of stem/progenitor cells in combination with a polyester fleece I-7 as an artificial interstitium supported the spatial generation of tubules during perfusion culture in chemically defined Iscove's Modified Dulbecco's Medium containing aldosterone $\left(1 \times 10^{-7} \mathrm{M}\right)$. In the present experiments we investigated if the use of different polyester fleeces (Posi-4 and Posi-5 in comparison to I-7) has any effect on generation, differentiation and spatial development of tubules.

In consequence, immunohistochemistry, transmission electron microscopy and scanning electron microscopy were performed. Since the specimens were not coated by extracellular matrix proteins, unique insights in the contact zone between the basal lamina, interstitial cells and surrounding polyester fibers can be obtained. Analyzing the specimens developing in I-7, Posi-4 and Posi-5 polyester fleeces by means of immune histochemistry and transmission electron microscopy illuminated that no cell biological differences could be observed. In contrast, scanning electron microscopy of generated tubules demonstrated that a difference in spatial distribution and different diameters of tubules could be registered.
\end{abstract}

It is concluded that tested I-7, Posi-4 and Posi-5 polyester fleeces appear as promising candidates to shelter stem/progenitor cells after implantation although they exhibit different spatial growth pattern.

Keywords: tissue engineering; polyester fleece; artificial interstitium; kidney; regeneration; stem/progenitor cells

\section{Introduction}

Since several years biomedical and clinical research is focusing on the use of stem/progenitor cells (s/pC) in renal injury and repair [1-6]. Two characteristic features, self-renewal and the ability to differentiate, make s/pC ideally adequate for cellular therapy of acute and chronic renal failures [7]. However, the success of this strategy is subject to a proper integration of the $\mathrm{s} / \mathrm{pC}$ in the diseased organ at the site of damage [8-10].

In the meantime different methods for $\mathrm{s} / \mathrm{pC}$ application were elaborated. The infusion over the capillary system is a frequently used method to administer these cells Figure 1a $[8,12]$. However, poor cell survival after application and no cell concentration at the site of necessary regeneration are the disadvantages of this application method $[11,13]$. Further contributions for kidney repair are the casual injection into diseased parenchyma Figure $1 \mathrm{~b}[14]$ and the subcapsular injection of s/pC Figure 1c [15-17]. Cells for repair are either injected as suspension [18] or after coating with extracellular matrix proteins [19]. These methods share the disadvantage that numerous foci of degenerated parenchyma cannot be reached by spot application. Thus, the amount of injected or implanted $\mathrm{s} / \mathrm{pC}$ in a diseased organ abides labile and cell concentration is not obtained at sites of need.

Independent of therapeutic application the $\mathrm{s} / \mathrm{pC}$ have to migrate from the site of implantation through the interstitial space into diseased areas of the kidney in order to terminate the degradation process and turn it in regeneration [20]. Thus, to support the repair of diseased parenchyma one has to elaborate the optimal site of implantation and to learn about model systems leading to renal tubular regeneration in combination with s/pC $[3,22]$.
In consequence, due to these needs we decided to investigate the adhesion of s/pC to a polyester fleece which can be implanted at the site of the earlier renal stem/progenitor cell niche located between the renal capsule and the outer cortex of parenchyma Figure 1d. Following this strategy it is possible to concentrate $\mathrm{s} / \mathrm{pC}$ within the fleece structures. This innovative delivery system is preferred because the concentrated cells can stay at their site of implantation between the capsule and the outer renal cortex during the initial phase of adaption. Further an optimal ratio between surface area and volume can be achieved in order to provide the diseased organ with a high density of s/pC [23]. Another advantage is the possibility to incorporate later growth factors in the fleece fibers playing a key role in tissue restoration and regeneration [24-26].

However, before the idea can be realized to implant s/pC within a fleece, numerous problems have to be considered. The correct selection of polyester fleece as support material for the adhesion of $\mathrm{s} /$ $\mathrm{pC}$ is dependent on several factors. The fleece fibers have to reflect a structured environment with tissue-specific mechanical properties. In

*Corresponding author: Will W. Minuth, Molecular and Cellular Anatomy University of Regensburg, University Street 31, D-93053 Regensburg, Germany Tel.:+49 (0)941 943 2876; Fax.: +49 (0)941 943 2868; Email: will.minuth@vkl.uniregensburg.de

Received July 19, 2011; Accepted July 27, 2011; Published July 29, 2011

Citation: Glashauser A, Denk L, Minuth WW (2011) Polyester Fleeces used as an Artificial Interstitium Influence the Spatial Growth of Regenerating Tubules. J Tissue Sci Eng 2:105. doi:10.4172/2157-7552.1000105

Copyright: (C) 2011 Glashauser A, et al. This is an open-access article distributed under the terms of the Creative Commons Attribution License, which permits unrestricted use, distribution, and reproduction in any medium, provided the original author and source are credited. 

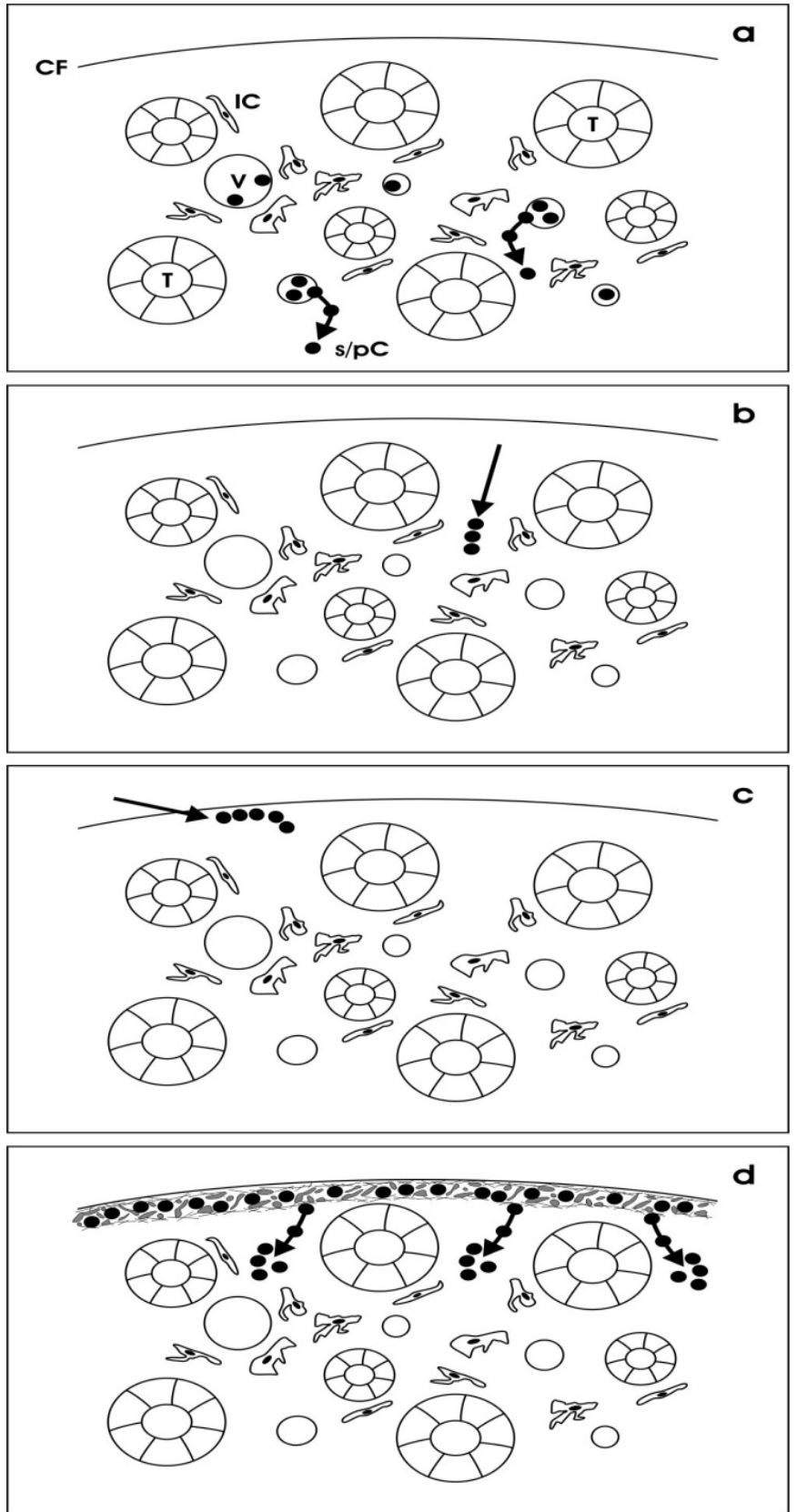

Figure 1: Schematic illustration of methods to apply stem/progenitor cells $(\mathrm{s} / \mathrm{pC})(\mathrm{a}-\mathrm{d})$. Schema depicts infusion via blood vessels $(\mathrm{a})$, by accidental injection of cell suspensions in the parenchyma (b), by subcapsular implantation of cell suspensions (c) and by subcapsular implantation of stem/ progenitor cells adhering to a biomaterial (d). Capsula fibrosa (CF), tubules (T), blood vessels $(\mathrm{V})$ and interstitial cells (IC).

addition, the fleece material must be biocompatible to $\mathrm{s} / \mathrm{pC}$, to diseased, regenerating and healthy renal parenchyma. Further cell adhesion, cellular spreading and proliferation are influenced by porosity such as pore shape, size, interconnectivity and orientation, surface chemistry, topology and architecture [27]. Even the diffusion of respiratory gas, small molecules, nutrients and metabolic products must be promoted [28]. Finally the mechanical features of the used biomaterial have to withstand in vivo forces until the regenerated parenchyma has sufficient stability to protect itself [10].
Previous and present culture experiments demonstrated that numerous renal tubules derived from $\mathrm{s} / \mathrm{pC}$ can be generated between two layers of polyester fleece I-7 [29-31], Posi-4 or Posi-5 [32]. Since the generation of tubules was performed without coating by extracellular matrix, it is possible to investigate the outer surface of the tubules, the interstitial space and the neighborhood to polyester fibers.

In consequence, the focus of interest in this study was directed to the formation of renal tubules within an artificial polyester interstitium needed for the future implantation of $\mathrm{s} / \mathrm{pC}$. Immunhistochemistry was performed to analyze the cell biological degree of differentiation, while transmission electron microscopy and scanning electron microscopy were made to obtain new information about the spatial distribution of tubules.

\section{Materials and Methods}

\section{Isolation of stem/progenitor cells $(\mathrm{s} / \mathrm{pC})$}

Both kidneys of one-day old anesthesized and sacrificed New Zealand rabbits were removed and cut into two parts as described earlier [33]. Tissue containing renal $\mathrm{s} / \mathrm{pC}$ was harvested from the outer cortex by stripping off the capsula fibrosa with fine forceps Figure 2a.

\section{Biomaterials}

To investigate the generation of tubules within an artificial interstitium a set of polyester fleeces, established I-7 (Walraf, Grevenbroich, Germany) versus Posi-4 and Posi-5 fleeces (Positech, Hallwil, Suisse), was tested.
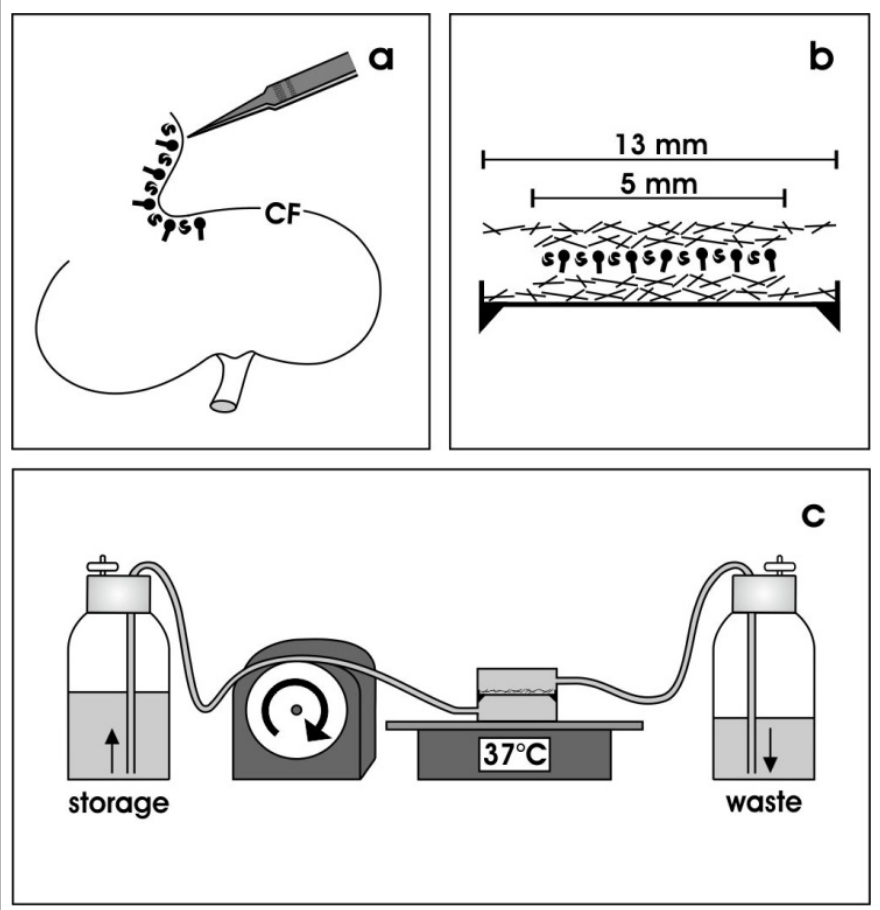

Figure 2: Schematic illustration of isolating renal stem/progenitor cells and generation of tubules at the interface of an artificial polyester interstitium (ac). By stripping off the capsula fibrosa (CF) from neonatal rabbit kidney renal stem/progenitor cells within mesenchyme and collecting duct ampullae can be isolated (a). To create an artificial interstitium renal stem/progenitor cells are mounted between layers of polyester fleece within a tissue carrier (b). During perfusion culture always fresh medium is transported (arrow) by a peristaltic pump. To maintain a constant temperature of $37^{\circ} \mathrm{C}$, the culture container is placed on a thermoplate and covered with a lid. 
1-7

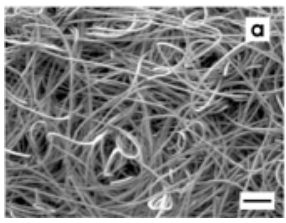

Figure 3: Scanning electron microscopy of $1-7$ (a), Posi-4 (b) and Posi-5 (c) polyester fleeces. SEM shows that fibers of these fleeces are detected in a longitudinal, transversal and oblique course. The fibers exhibit a homogenous composition and a smooth surface without recognizable protrusions or roughness. Posi-4 (b) and Posi-5 (c) polyester fleeces show melted fibers at crossing points and interconnected pores which were not obtained in I-7 (a).

\section{Perfusion culture system}

For the generation of renal tubules, the isolated embryonic tissue was placed between two punched-out polyester fleeces measuring 5 $\mathrm{mm}$ in diameter. The sandwich-like configuration creates an artificial interstitium with the isolated tissue in the middle and the polyester fleece covering the upper and lower side. Then the set-up was placed between additional fleece layers measuring $13 \mathrm{~mm}$ in diameter and mounted in a Minusheet ${ }^{\mathbb{B}}$ tissue carrier (Minucells and Minutissue, Bad Abbach, Germany) Figure 2b. This configuration kept the isolated renal tissue in plane position and prevented damage during culture. Perfusion culture was performed in a container (Minucells and Minutissue) with horizontal flow conditions for 13 days at $37^{\circ} \mathrm{C}$ Figure $2 c$.

An IPC N8 peristaltic pump (Ismatec, Wertheim, Germany) transported always fresh Iscove's Modified Dulbecco's Medium (IMDM including phenolred, GIBCO/Invitrogen, Karlsruhe, Germany) at a rate of $1.25 \mathrm{ml} / \mathrm{h}$. To sustain a constant $\mathrm{pH}$ of 7.4 under atmospheric air containing $0.3 \% \mathrm{CO}_{2}$ up to $50 \mathrm{mmol} / \mathrm{l}$ HEPES (GIBCO) was added. Supply of an antibiotic-antimycotic cocktail (1\%, GIBCO) impeded contamination of the medium. For tubulogenic development aldosterone was added at the concentration of $1 \times 10^{-7} \mathrm{M}$ (Fluka, Taufkirchen, Germany).

\section{Histochemical labeling}

After perfusion culture was terminated the sandwich set-ups containing renal tissue within two layers of polyester fleece $(5 \mathrm{~mm}$ diameter) were embedded in $1 \%$ agarose (Serva, Heidelberg, Germany), surrounded by TissueTek (O.C.T. ${ }^{\mathrm{TM}}$ COMPOUND, Sakura Finetek, Zoeterwoude, Netherlands) and frozen at $-80^{\circ} \mathrm{C}$. To analyze cell biological features $20 \mu \mathrm{m}$ thick cryosections were made, fixed in ice cold ethanol, washed several times with phosphate buffered saline (PBS) and incubated for 30 minutes with blocking solution (PBS, pH 7.5, 10\% horse serum, GIBCO, 1\% bovine serum albumin, Serva). For soybean agglutinin-labeling (SBA, Vector, Burlingame, USA) the samples were exposed to fluorescein-isothiocyanate (FITC)-conjugated lectin diluted 1:2000 in blocking solution for 45 minutes. For immunohistochemical label anti-laminin $\gamma 1$ (kindly provided by Dr. L. Sorokin, Lund, Sweden) was used undiluted, anti-cingulin (Progen Biotechnik, Heidelberg, Germany) was applied 1:10 and anti-collagen type III (III-53, Calbiochem, Schwalbach, Germany) was added 1:250 in blocking solution for one hour. After washing several times with 1 $\%$ BSA in PBS the specimens were incubated for 45 minutes with goatanti-rat-IgG-rhodamine, donkey-anti-guinea-pig-IgG-fluoresceinisothiocyanate or donkey-anti-mouse-IgG-fluorescein-isothiocya-nate (Jackson Immunoresearch Laboratories, West Grove, USA) diluted 1:50 in PBS containing 1\% BSA. Following several washes with PBS the sections were embedded with Slow Fade Light Antifade Kit (Molecular Probes, Eugene, USA) and then analyzed using an Axioskop 2 plus microscope (Zeiss, Oberkochen, Germany). Fluorescence images were taken with a digital camera at a standard exposure time of 1.3 seconds and thereafter processed with Corel DRAW Graphic Suite X5 (Corel Corporation, Otawa, Canada).

\section{Scanning Electron Microscopy (SEM)}

To analyze the spatial distribution of generated tubules by SEM, specimens were fixed in $70 \%$ ethanol, dehydrated in a graded series of ethanols, transferred to acetone, and critical-point dried in carbon dioxide. Finally, samples were sputter-coated with gold (Polaron E 5100, Watford, GB) and examined in a scanning electron microscope DSM 940 A (Zeiss, Oberkochen, Germany). Images of the screen were taken by a Pentax SLR Digital camera and thereafter processed with Adobe Photoshop (Adobe, California, USA) and Corel DRAW Graphic Suite X5.

\section{Transmission Electron Microscopy (TEM)}

For transmission electron microscopy (TEM) the specimens were fixed in $2 \%$ glutaraldehyde containing $0.1 \mathrm{M}$ sucrose in $0.1 \mathrm{M}$
$1-7$
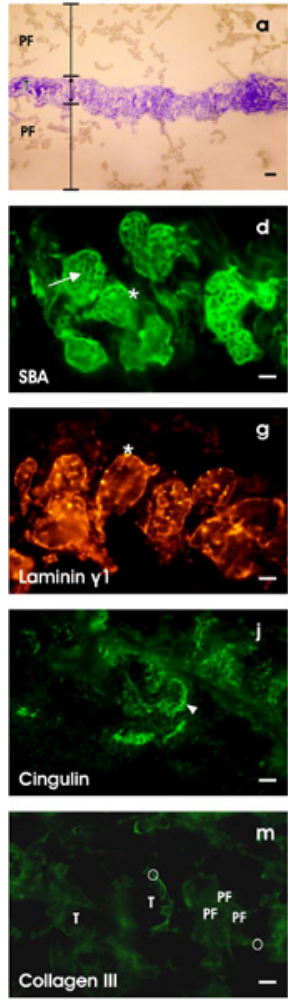

Figure 4: Toluidine blue staining (4a-c) and $h$
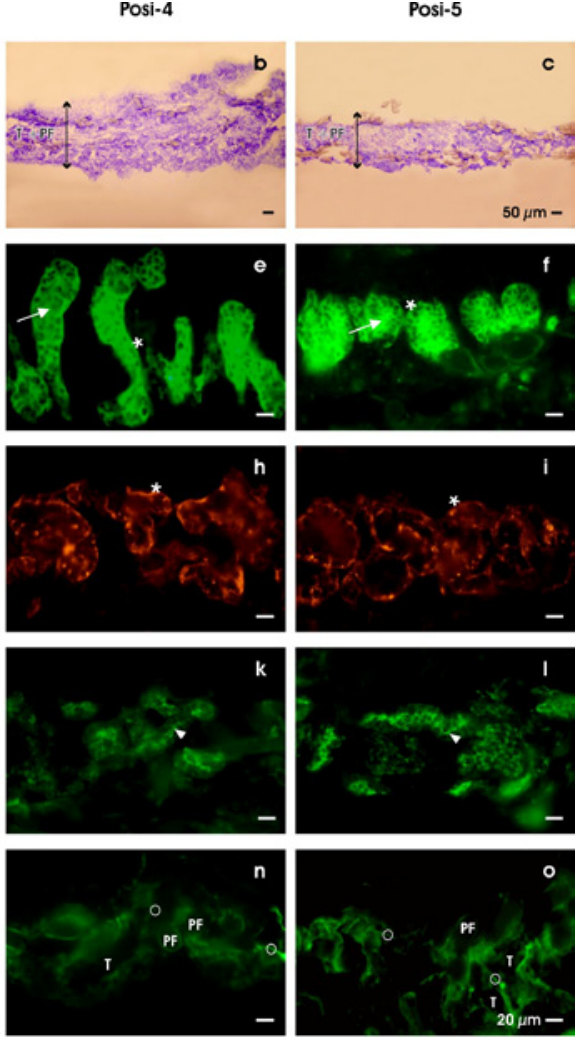
$\mathrm{f})$, Laminin y $1(4 \mathrm{~g}-\mathrm{i})$, Cingulin $(4 \mathrm{j}-\mathrm{I})$ and Collagen III $(4 \mathrm{~m}-\mathrm{O})$. Toludine blue stained cryosections show numerous tubules $(T)$ covered at the upper and lower side by $1-7$ fleece layers consisting of polyester fibers (PF) (a). At Posi4 (b) and Posi-5 (c) polyester fleeces toludine blue stain demonstrates that tubules develop between the fleece layers as well as between the polyester fleece fibers. Cryosections reveal after SBA-label numerous tubules containing a basal lamina (asterisk) and a lumen (arrow) (d-f). The basal lamina of all generated tubules is positive for Laminin y $1(\mathrm{~g}-\mathrm{i})$. Positive label for Cingulin exhibt polarization in all of the epithelial cells $(j-I)$. Collagen type III $(m-0)$ labels the basal lamina as well as interstitial fibers. Newly synthesized extracellular matrix $(\mathrm{O})$. 

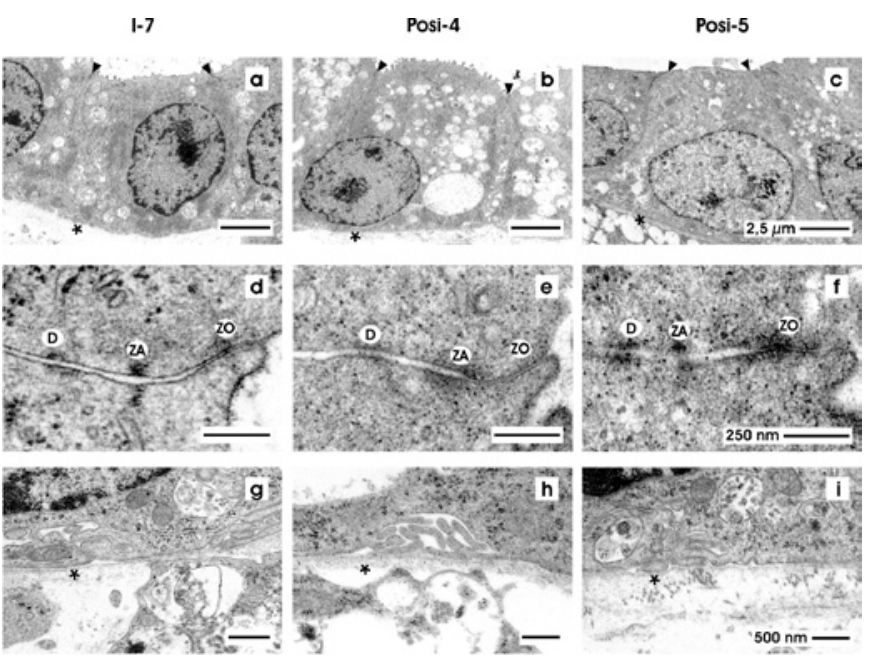

Figure 5: Transmission electron microscopy on generated tubules after 13 days of culture (a-i). Surface view demonstrates that tubules contain a polarized epithelium with isoprismatic cells. At the border between the luminal and lateral plasma membrane in all of the series a tight junctional complex is developed (arrow head). The basal side of the epithelium rests on a basal lamina (asterisk) (a-c). The tight junctional complex consists of a zonula occludens (ZO), zonula adhaerens (ZA), and a desmosome (D) (d-f). At the basal aspect a continously developed basal lamina (asterisk) can be observed $(\mathrm{g}-\mathrm{i})$.

cacodylate buffer $(\mathrm{pH} 7,5)$ over night at $4^{\circ} \mathrm{C}$. After several washes with PBS tissue was post fixed in $1 \mathrm{M}$ PBS containing 1\% osmium tetroxide. After rinsing in PBS specimens were dehydrated in graded series of ethanols and embedded in Epon. Polymerization was performed at $60^{\circ} \mathrm{C}$ for $48 \mathrm{~h}$. Ultrathin sections were obtained with a diamond knife on an ultramicrotome EM UC6 (Leica GmbH, Wetzlar, Germany). Sections were collected onto grids (200 mesh) and contrasted using $2 \%$ uranyl acetate and lead citrate. For TEM studies, grids were analyzed by a TEM Zeiss 902 (Zeiss, Oberkochen, Germany). Electron micrographs were recorded digitally using a slow scan CCD camera and thereafter processed with Adobe Photoshop (Adobe, California, USA) and Corel DRAW Graphic Suite X5.

\section{Results}

\section{Pattern of the fleece surfaces}

The present experiments were performed to analyze the spatial development of renal tubules within three different polyester fleeces. As revealed by SEM the fleeces I-7 (Figure 3a), Posi-4 (Figure 3b) and Posi-5 Figure $3 \mathrm{c}$ themselves exhibited different properties. All of them demonstrated numerous polyester fibers lining in a longitudinal, transversal and oblique course. At the crossing site of I-7 fleece fibers no remarkable crosslinking feature could be detected. Due to the lack of product information mechanically crosslinking was assumed.

The average diameter of I-7 fleece fibers amounted to $10 \mu \mathrm{m}$. In contrast to I-7 polyester fleece Figure $3 \mathrm{a}$ the fibers of Posi-4 Figure $3 \mathrm{~b}$ and Posi-5 Figure $3 \mathrm{c}$ seemed to be welded at the crossing sites to each other. Pursuant to the provider of the Posi fleeces the crosslinking was done solely by heat. Further the Posi fleeces differed in their average diameter of the fibers. The fiber diameter of Posi-4 fleece was $25 \mu \mathrm{m}$ and the mean diameter of Posi-5 fibers was $34 \mu \mathrm{m}$. In both cases the shape changed from round to oval at the crossing point of the fibers. Another difference among Posi- 4 and Posi- 5 was the thickness of the fleece layers. As indicated by the supplier, the thickness of Posi- 4 was
$0.13 \mu \mathrm{m}$ and of Posi-5 it was $0.17 \mu \mathrm{m}$. Water porosity was in Posi-4 fleece $1480 \mathrm{~L} / \mathrm{m}^{2} / \mathrm{S}$, while in Posi-5 fleece $1200 \mathrm{~L} / \mathrm{m}^{2} / \mathrm{S}$ was typical. Micron rating showed a descent from $40 \mu \mathrm{m}$ in Posi-4 fleece to $30 \mu \mathrm{m}$ in Posi-5 fleece.

\section{Development of tubules within polyester fleeces}

To analyze the spatial distribution of generated tubules frozen sections were made vertically to the fleece surface. Staining with toluidine blue showed that generated specimens contained numerous tubules at the interface of the artificial interstitium made with polyester fleece I-7 Figure 4a, Posi-4 Figure 4b or Posi-5

Figure 4c. The most obvious result was that application of I-7 fleece showed tubules exactly orientated at the interface between the upper and lower fleece layer Figure $4 \mathrm{a}$. In contrast, the fleece fibers of Posi-4 Figure $4 \mathrm{~b}$ and Posi-5 Figure $4 \mathrm{c}$ did not cover the generated tubules at the upper and lower side but are found to be widely integrated within the tissue.

In the next series of experiments generated tissue was labelled
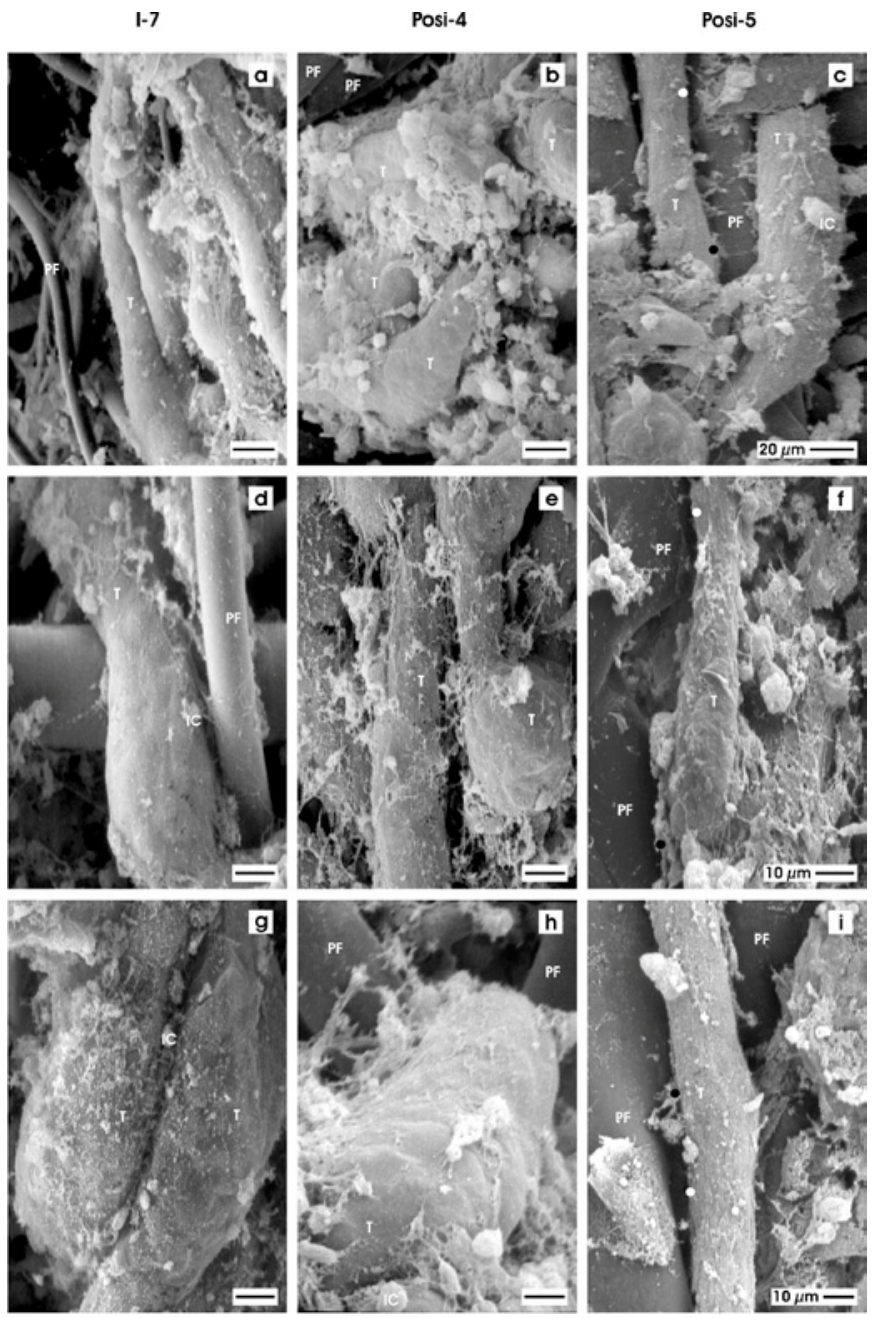

Figure 6: Scanning electron microscopy of tubules growing on polyester fleece I-7 (a, d, g), Posi-4 (b, e, h) and Posi-5 (c, f, i). In all of the cases it is observed that the tubules $(T)$ are in more (black dot) or less (white dot) neighborhood to polyester fibers (PF). The surface of tubules is covered by a basal lamina. Occasionally interstitial cells (IC) can be recognized. 

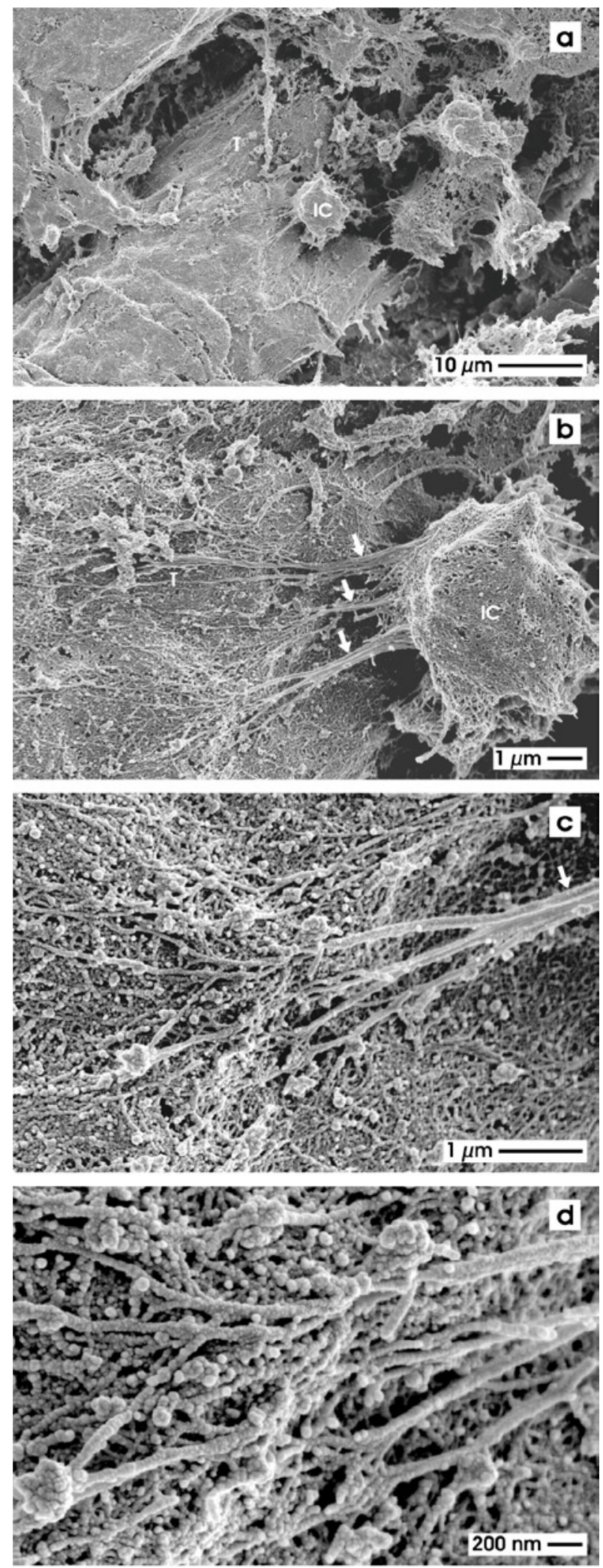

Figure 7: Scanning electron microscopy of an interstitial cell (IC) contacting a generated tubule $(T)$ by cellular protrusions (thick arrow) within Posi-5 fleece $(a, b)$. Higher magnification shows protrusions which are interwoven with the basal lamina of the tubule (c, d). An exact transition from a cell protrusion to the lamina fibroreticularis at the basal lamina cannot be recognized. with soybean agglutinin (SBA) to elucidate in more detail the spatial occurrence of tubules. In I-7 Figure 4d, in Posi-4 Figure 4e and in Posi5 specimens Figure $4 \mathrm{f}$ numerous SBA positive tubules were found. In all of them a lumen (arrow) and a basal lamina (asterisk) was detected.

To investigate specific cell biological differentiation generated tubules were labelled with antibodies. The intensive reaction for laminin $\gamma 1$ at the basal region of generated tubules indicated that in series with I-7 Figure $4 \mathrm{~g}$, Posi-4 Figure $4 \mathrm{~h}$ as well as with Posi-5 Figure 4i fleece a basal lamina had developed during 13 days of culture. Further intense label for cingulin in the luminal portion of generated tubules of I-7 Figure 4j, Posi-4 Figure 4k and Posi-5 Figure $4 \mathrm{l}$ specimens indicated a functional polarization between the luminal and lateral plasma membrane of tubule cells. Strong label for Na/K-ATPase $\alpha 5$ and TROMA-I in I-7, Posi- 4 and Posi- 5 specimens confirmed that nephron-specific characteristics were up-regulated as it was shown earlier [32].

Finally, staining with anti-collagen type III revealed that the basal aspect of generated tubules as well as the interstitial space in I-7 Figure 4m, Posi-4 Figure 4n and Posi-5 Figure 4o samples exhibited intense label. In addition, a series of fibers is spanning between generated tubules and polyester fibers of the artificial interstitium as seen in specimens of I-7 Figure 4m, Posi-4 Figure 4n and Posi-5 Figure 4o.

\section{Transmission electron microscopical features of generated tubules}

Label for laminin $\gamma 1$ and cingulin showed that polarization of epithelial cells was established during generation of tubules. To obtain more information transmission electron microscopy (TEM) of generated tubules at the interface of polyester fleeces I-7 Figure 5a,d,g, Posi- 4 Figure 5b,e,h and Posi-5 Figure 5 c,f,i was performed. It was seen that tubules were encountered in the neighborhood of the polyester fibers of each of the fleeces. In all three cases generated tubules consisted of an isoprismatic epithelium bordering on the apical side a lumen. A tight junctional complex separates the luminal from the basolateral plasma membrane. At the basal aspect a constantly developed basal lamina (asterisk) was found. Each cell contained a nucleus. Within the cytoplasm numerous vacuoles respectively lysosomal elements of different size and content were detected.

Immunohistochemistry depicted that cingulin was localized at the luminal cell aspect Figure 4j-1. Also the surface view illuminated that the luminal and basolateral plasma membranes were separated by a tight junctional complex in I-7, Posi- 4 and Posi-5 specimens Figure 5ac, arrow head. To elucidate if this complex consists of typical structures higher magnification in TEM was applied Figure 5d-f. In all three cases the luminal and lateral plasma membranes of neighboring epithelial cells were separated by an intact tight junctional complex consisting of a zonula occludens (ZO), zonula adhaerens (ZA) and a desmosome (D) indicating that a functional sealing was established during culture. Most interesting was the basal aspect of the epithelium Figure $5 \mathrm{~g}$ i. At the contact site between the basal lamina and the basal plasma membrane infoldings could be observed indicating a high transport capacity.

The generated tubules were facing at the basal side an artificial interstitium. For that reason it was of importance to analyze the construction of the basal lamina. Cross sections of the basal aspect of the epithelium in I-7 Figure 5g, Posi-4 Figure 5h and Posi-5 Figure 5i specimens clearly showed a constantly developed basal lamina consisting of a lamina rara, lamina densa and lamina fibroreticularis Figure 5g-i. 


\section{Scanning electron microscopy at the interface of an artificial interstitium}

During generation of renal tubules the surrounding is not stacked by proteins derived from a coating process. This situation allowed the investigation of the outer tubule surface by scanning electron microscopy (SEM) Figure 6 Of special interest is the interface between the basal lamina of tubules and the surrounding polyester fibers, the occurrence of interstitial cells and the deposition of synthesized interstitial matrix.

\section{SEM analysis of generated tubules within polyester fleece I-7}

SEM shows that generated tubules were growing in a more or less parallel fashion to the polyester fibers of the fleece Figure 6a, d, g. The outer diameter of generated tubules was found to range between $14 \mu \mathrm{m}$ and $49 \mu \mathrm{m}$. The basal aspect of each tubule was covered by a continuously developed basal lamina. Looking at the outer surface of the tubules interstitial cells and numerous fibers obviously consisting of newly synthesized extracellular matrix proteins could be detected Figure $6 \mathrm{a}, \mathrm{d}, \mathrm{g}$. The synthesized fibers of extracellular matrix were interposed between generated tubules and single I-7 polyester fleece fibers as well as between contiguous tubules Figure 6d, g. Although the tubules grew in the vicinity of the polyester fibers they had only loose and astonishingly irregular contact to the fleece fibers.

\section{SEM analysis of generated tubules within polyester fleece Posi-4}

Scanning electron microscopy of Posi-4 fleece depicts generated tubules in a parallel growth Figure $6 \mathrm{~b}$, e, h. From time to time dichotomous branching of tubules could be observed. Similar to I-7 fleece Figure $6 \mathrm{a}, \mathrm{d}, \mathrm{g}$ the diameter of generated tubules in between Posi- 4 fleeces is ranging between $20 \mu \mathrm{m}$ to $46 \mu \mathrm{m}$. The complete outer surface of the generated tubules was consistently covered by a basal lamina Figure $6 \mathrm{~b}, \mathrm{e}, \mathrm{h}$. Further a fine network of extracellular matrix proteins and interstitial cells is surrounding the outer surface of the basal lamina.

\section{SEM analysis of generated tubules within polyester fleece Posi-5}

SEM of polyester fleece Posi-5 illustrates that some generated tubules grew in parallel fashion Figure $6 c$, f,i, while others exhibited dichotomous branching (not shown). In this experimental series the diameter of tubules was between 17 and $33 \mu \mathrm{m}$. Some of the tubules had only a loose contact to the polyester fibers Figure 6c, f, I; (black dot), while others had no contact to them (white dot). The surface of generated tubules was covered by a continuously developed basal lamina. The outer surface of this lamina was covered by irregular strands of newly synthesized extracellular matrix. Occasionally interstitial cells (IC) are contacting the basal lamina and synthesized extracellular matrix Figure 6c, f, i.

\section{Focus to the outer surface of generated tubules}

Since the specimens were not coated by extracellular matrix proteins the interface between tubules, interstitial cells and polyester fleece fibers now can be investigated by ultrastructural methods. SEM of I-7, Posi-5 and Posi-4 specimens depicts that the outer surface of generated tubules is covered by interstitial cells and a network of conspicuous filigreed fibers consisting obviously of newly synthesized extracellular matrix Figure 6. Thus, more information about the connection between interstitial cells and the outer surface of tubules was obtained by higher resolution. SEM images of generated tubules within polyester fleece Posi-5, for example, illlustrated interstitial cells (IC) on their surface Figure 7. These cells exhibit a diameter of 7-8 $\mu \mathrm{m}$ and were distributed in irregular distances Figure $7 \mathrm{a}, \mathrm{b}$. They contacted the tubule by cellular protrusions. The length of these protrusions ranged from $4 \mu \mathrm{m}$ to $10 \mu \mathrm{m}$. The diameter spanned from $80 \mathrm{~nm}$ up to $1 \mu \mathrm{m}$ depending on the distance of the interstitial cell to the basal lamina of the tubule. During extension the diameter of the protrusions became smaller. Before reaching the surface of the tubule the interstitial cell processes showed several dichotomous branchings and became thinner Figure $7 \mathrm{~b}, \mathrm{c}$. At their endings the branched cellular protrusions of interstitial cells demonstrated a rough surface which looked like a string of pearls. The ends of the protrusions are woven into the outer surface of the lamina fibroreticularis Figure $7 \mathrm{~d}$. Most obvious is that the transition form the cellular processes to the collagen fibers of the lamina fibroreticularis could not be clearly discriminated.

Further we investigated the contact between tubules and polyester fibers. This contact is exemplarily demonstrated on Posi-4 fleeces (Figure 8). The surrounding of the tubules exhibited fibers lining from the lamina fibroreticularis within the basal lamina of the tubule to the surface of neighboring polyester fibers Figure 8a. These fibers of newly synthesized extracellular matrix were arranged in a woven netlike structure Figure $8 \mathrm{~b}$. From the tubule towards the surface of the polyester fiber the net-like structure changed from a broad-meshed to a close-meshed network Figure $8 \mathrm{c}$. An integration of polyester fibers into the tubules was not obvious. In contrast, the tubules stayed in distance to the polyester fiber Figure 8d.

Looking over all, the tested I-7, Posi-4 and Posi-5 fleeces appear as promising candidates to harbour $\mathrm{s} / \mathrm{pC}$ during regeneration of parenchyma in acute and chronic renal failure, although they show a different spatial growth pattern of generated tubules.

\section{Discussion}

The present experiments were performed to investigate by cell biological Figure 4 and ultrastructural methods Figure 5,6,7,8 the spatial growth of tubules within three selected polyester fleeces. All applied polyester fleeces I-7, Posi- 4 and Posi- 5 exhibit biocompatibility, although they differ in crosslinking, thickness, porosity, fiber diameter and appearance of the pores [32]. However, these structural differences do not influence the generation of tubules and the polarization of epithelial cells. This could be recognized based on the formation of a tight junctional complex separating the luminal and lateral plasma membrane of tubule cells.

Regarding the spatial growth pattern a difference in tubule growth could be observed. The ingrowth of tubules between polyester fleece fibers is rather high in Posi-4 Figure $4 \mathrm{~b}$ but lower in Posi-5 Figure $4 \mathrm{c}$ polyester fleece. In the case of I-7 polyester fleece a tubule ingrowth could not be observed Figure 4a. These findings seem to correlate with the water porosity of the used fleeces [32], which implied that a higher porosity (Posi-4) supports the development and ingrowth of tubules. This observation is sustained by several studies emphasizing a high porosity for ensuring attraction for cells $[10,34,35]$. According to Zippel et al. interconnected pores allow cell ingrowth and vascularization, a higher porosity results in greater cell ingrowth [27]. The above mentioned interconnected pores between fleece fibers were observed in Posi-4 and Posi-5 polyester fleece and consequently they can be a reason for the demonstrated integration and spatial distribution of tubules.

Both light and electron microscopy showed that the development of tubules occurs independently if I-7, Posi- 4 or Posi- 5 polyester fleece 

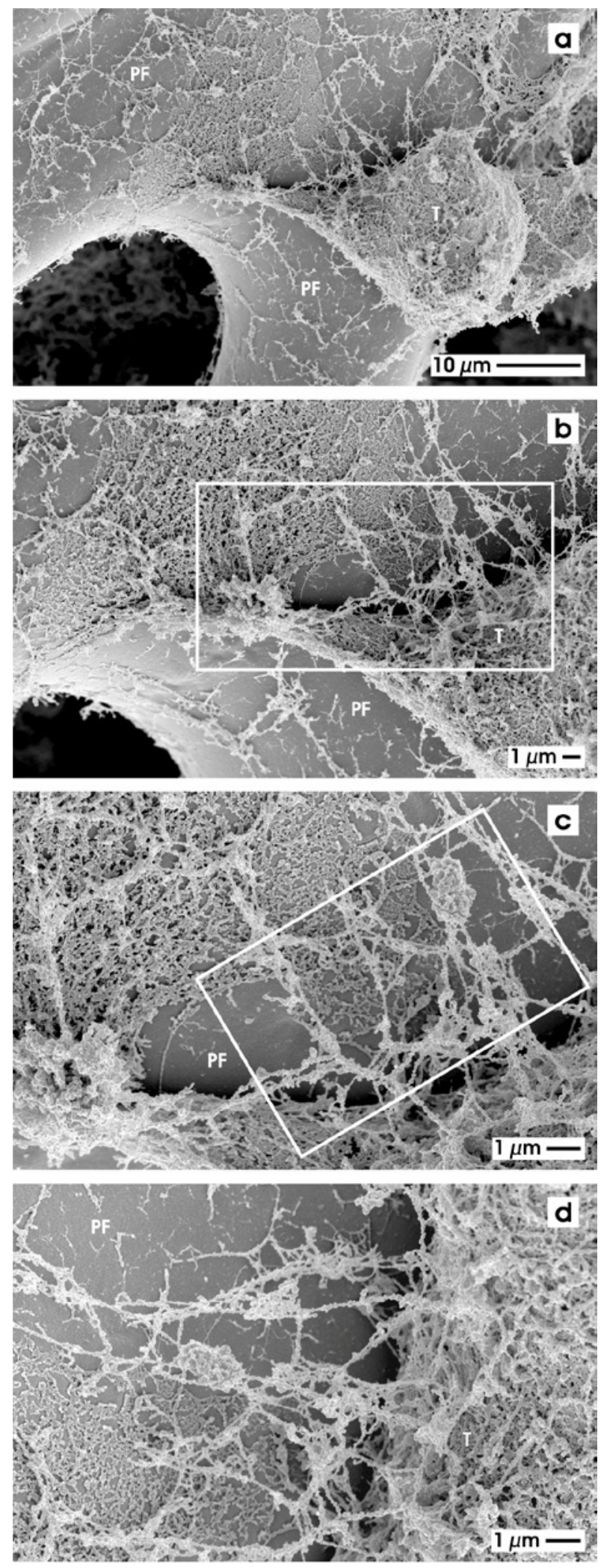

Figure 8: Scanning electron microscopy of a generated tubule $(T)$ contacting a polyester fiber (PF) of Posi-4 fleece (a). Generated tubules are grown in the close vicinity of polyester fibers. Between the basal lamina of generated tubules and the polyester fibers newly synthesized extracellular matrix (square) is detected $(b, c, d)$. were used as artificial interstitium Figure 4. Immunohistochemistry of these specimens further demonstrated that the generated tubules exhibit the same cell biological differentiation profile. In all three cases tubules with a completely developed basal lamina and tight junctional complexes could be demonstrated. Within the cytoplasm numerous lysosomal elements respectively vacuoles were detected on transmission electron micrographs Figure 5. The increased occurrence of lysosomal elements and vacuoles within in the cytoplasm could illuminate a possible implication of endo- and/or exocytosis. At the basolateral plasma membrane the degree of protrusions and infoldings indicates a high transport capacity Figure $5 \mathrm{~g}, \mathrm{~h}$, i [36,37]. A higher transport capacity gives reason to expect a high cell activity which could be correlated with a high endo- and/or exocytosis rate. Consequently many vacuoles and lysosomal elements can be observed.

Since the interstitial space between the generated tubules was not stacked by proteins from a coating process, it was possible to explore the outer surface of generated tubules by SEM. Hence, the observation of generated tubules within different polyester fleeces showed a difference in the diameter of the tubules Figure 6. Within I-7 Figure $6 \mathrm{a}, \mathrm{d}, \mathrm{g}$ polyester fleece the outer tubule diameter ranged between $14 \mu \mathrm{m}$ and $49 \mu \mathrm{m}$, within Posi- 4 Figure $6 \mathrm{~b}$, e, h polyester fleece between $20 \mu \mathrm{m}$ and $46 \mu \mathrm{m}$ and within Posi-5 Figure $6 \mathrm{c}$, f, i polyester fleece between $17 \mu \mathrm{m}$ and $33 \mu \mathrm{m}$. These wide and different ranges of diameters within the used polyester fleeces cannot be explained by differences during culture or in the fixation procedure because all of the tissues were treated the same. Most probably, the different diameters of generated tubules within the artificial interstitium might be explained by the occurrence of various tubules. In the kidney of two weeks old Albino rats a proximal tubular diameter of $42,7 \mu \mathrm{m}$ and a distal tubular diameter of $26,5 \mu \mathrm{m}$ was measured [38]. As described by Knepper et al. the mean proximal tubular diameter in rabbit kidney was $37 \mu \mathrm{m}$ and the average distal tubular diameter amounted to $25 \mu \mathrm{m}$ [39]. Cole et al. have demonstrated that during development of rabbit kidney an increase of the size of proximal tubule cells arose. If the size of proximal tubule cells increases, the outer diameter of the proximal tubule will also increase [40]. However, the immunohistochemical profile militates for the development of the same kind of tubules. Further the applied markers indicate the formation of collecting tubules. In consequence, the various tubule diameters and the different stage of tubule development seemed to be caused by surface features of Posi- 4 , Posi-5 and I-7 polyester fleece.

In this study the basal lamina of the generated tubules was covered by bright particles most probably extracellular matrix with different shape Figure 6, 7. These findings are in conformity with previous studies [41]. As yet the nature of these particles remains to be elaborated. Whereas nephrogenesis and terminal differentiation of renal tubules are dependent on extracellular matrix molecules like for example cell adhesion molecules [42-46], it seems reasonable to presume that these molecules are found on the surface of generated tubules and interstitial cells.

In the present study the discovered interstitial cells showed cellular processes with numerous bifurcations which contacted the basal lamina of generated tubules and which seem to be interwoven with the lamina fibroreticularis Figure 7. These observations are in accordance with previous experiments. For example, Lewis et al. showed that interstitial, fibroblast-like cells have an irregular, stellate shape with numerous long and thin processes, which appear to contact and to adhere to the basement membrane of adjacent tubules [47]. Depending on their location within the kidney and on their functional state the 
fibroblast phenotype shows some variations $[48,49]$. The observed cells were thought to represent "fibroblast-like" cells because they adhere to the generated tubules by cellular protrusions and their changed shape could be based on the location or the functional state [47-50]. The previous report by McAuliffe, who found in DI rats an almost total absence of interstitial cell processes, could not be confirmed in our study [51]. By SEM, Takahashi-Iwanaga et al. described cellular processes with a length of $10 \mu \mathrm{m}$ and a decrease of the diameter from the cellular primary, to secondary and to tertiary processes [52]. These facts coincide with our results Figure $7 \mathrm{c}$, d. Processes of interstitial cells with tapering ends or processes corresponding to flat pierced leaves could not be observed [52,53]. In the present study the processes do not seem to end but rather are interwoven with the lamina fibroreticularis of the generated tubules. It has been shown by transmission electron microscopy that the lamina fibroreticularis acts as connecting element to the interstitial space [41]. These adhesions and connections to the basal lamina of the generated tubules suggest that cross-talk between epithelial cell and interstitial, "fibroblast-like" cell might be mediated by mechanical forces $[53,54]$.

The present SEM observations stated that generated tubules are fastened to the polyester fibers by extracellular matrix fibers resulting in a net-like structure Figure 8. These fibers were not existent after isolation of $\mathrm{s} / \mathrm{pC}$, but they were synthesized during perfusion culture [55]. A feature of the fibers is collagen type III $[55,56]$. This component is also found on tubules within the kidney and is part of the renal interstitium [57-60]. It is established that collagen synthesis is induced by aldosterone [61-63]. Therefore the appearance of collagen fibers in our cultures can be a consequence of the administered aldosterone. As described by Lemley and Kriz the collagen type III fibers form a network enveloping the tubules [64]. A net-like structure of the extracellular matrix at the surface of the tubules could partly be observed in our study. Collagen fibers are known to be part of scaffolding function [53]. These findings make it reasonable to assume that the observed net-like structure of the connecting element between generated tubules and a polyester fleece is part of the above mentioned scaffolding function.

\section{Conclusion}

In this study we demonstrated that the development and biological differentiation of renal tubules is not dependent on the chosen polyester fleece used as artificial interstitium. But ingrowth of tubules in the polyester fleece layers can only be observed if polyester fleeces with interconnected pores like Posi- 4 or Posi-5 polyester fleece are used as artificial interstitium. In contrast, I-7 polyester fleece prevented in growth of tubules in the space between the fibers. Further interstitial cells lining with long processes to the tubules and extracellular matrix fibers seem to act as connecting elements. This important observation was possible, because the interface between tubules and artificial interstitium is not stacked by proteins derived from a coating process.

\section{References}

1. Hammerman MR (2004) Treatment for end-stage renal disease:an organogenesis/tissue engineering odyssey. Transpl Immunol 12:211-218.

2. Hammerman MR (2004) Organogenesis of kidneys following transplantation of renal progenitor cells. Transpl Immunology 12:229-239.

3. Atala A (2008) Advances in tissue and organ replacement. Curr Stem Cell Res Ther 3:21-31.

4. Rookmaaker MB, Verhaar MC, van Zonneveld AJ, Rabelink TJ (2004) Progenitor cells in the kidney: biology and therapeutic perspectives. Kidney Int 66:518-522.

5. Koh CJ,Atala A (2004) Tissue engineering, stem cells, and cloning: opportunities for regenerative medicine. Journal of the American Society of Nephrology: J Am Soc Nephrol 15:1113-1125.
6. Aboushwareb T, Atala A (2008) Stem cells in urology. Nat Clin Prac Urol 5:621631.

7. Imai N, Kaur T, Rosenberg ME, Gupta S (2009) Cellular therapy of kidney diseases. Semin Dial 22: 629-635.

8. Bussolati B, Camussi G (2007) Stem cells in acute kidney injury. Contrib Nephrol156: 250-258.

9. Humphreys BD, Bonventre JV (2007) The contribution of adult stem cells to renal repair. Nephrol Ther 3: 3-10.

10. Kim BS, Mooney DJ (1998) Development of biocompatible synthetic extracellular matrices for tissue engineering. Trends Biotechnol 16: 224-230.

11. Burst VR, Gillis M, Pütsch F, Herzog R, Fischer JH, Heid P, et al. (2010) Poor cell survival limits the beneficial impact of mesenchymal stem cell transplantation on acute kidney injury. Nephron Exp Nephrol 114: e107-16.

12. Caldas HC, Fernandes IMM, Gerbi F, Souza AC, Baptista MASF, et al. (2008) Effect of whole bone marrow cell infusion in the progression of experimental chronic renal failure. Transplant Proc 40: 853-855

13. Ding F, Humes HD (2008) The bioartificial kidney and bioengineered membranes in acute kidney injury. Nephron Exp Nephrol 109: e118-22.

14. Yokoo T, Kawamura T (2009) Xenobiotic kidney organogenesis: a new avenue for renal transplantation. J Nephrol 22:312-317.

15. Roufosse C, Cook HT (2008) Stem cells and renal regeneration. Nephron Exp Nephrol 109: e39-45.

16. Al-Awqati Q, Oliver JA (2006) The kidney papilla is a stem cells niche. Stem Cell Rev 2: 181-184.

17. Lange $C$, Tögel F, Ittrich $H$, Clayton F, Nolte-Ernsting $C$, Zander AR, et al (2005) Administered mesenchymal stem cells enhance recovery from ischemia/ reperfusion-induced acute renal failure in rats. Kidney Int 68: 1613-1617.

18. Patschan D, Plotkin M, Goligorsky MS (2006) Therapeutic use of stem and endothelial progenitor cells in acute renal injury: ça ira. Curr Op Pharmacol 6:176-183.

19. Ratliff BB, Ghaly T, Brudnicki P, Yasuda K, Rajdev M, et al. (2010) Endothelia progenitors encapsulated in biartificial niches are insulated from systemic cytotoxicity and are angiogenesis competent. Am J Physiol Renal Physiol 299 F178-86.

20. Bussolati B, Tetta C, Camussi G (2008) Contribution of stem cells to kidney repair. Am J Nephrol 28: 813-822.

21. Hammerman MR (2006) Cellular therapies for kidney failure. Expert Opin Bio Ther 6: 87-97.

22. Atala A (2008) Bioengineered tissues for urogenital repair in children. Pediatr Res 63: 569-575.

23. Kim SS, Park HJ, Han J, Gwak SJ, Park MH, et al (2007) Improvement of kidney failure with fetal kidney precursor cell transplantation. Transplantation 83: $1249-1258$.

24. Levenberg S, Burdick JA, Kraehenbuehl T, Langer R (2005) Neurotrophininduced differentiation of human embryonic stem cells on three-dimensional polymeric scaffolds. Tissue Eng 11: 506-512.

25. Dodla MC, Bellamkonda RV (2008) Differences between the effect of anisotropic and isotropic laminin and nerve growth factor presenting scaffolds on nerve regeneration across long peripheral nerve gaps. Biomaterials 29: 33 46.

26. Midha R, Munro CA, Dalton PD, Tator CH, Shoichet MS (2003) Growth factor enhancement of peripheral nerve regeneration through a novel synthetic hydrogel tube. J Neurosurg 99:555-565

27. Zippel N, Schulze M, Tobiasch E (2010) Biomaterials and mesenchymal stem cells for regenerative medicine. Recent Pat Biotechnol 4:1-22

28. Hollister SJ (2005) Porous scaffold design for tissue engineering. Nat Mate $4: 518-524$

29. Heber S, Denk L, Hu K, Minuth WW (2007) Modulating the development of renal tubules growing in serum-free culture medium at an artificial interstitium. Tissue Eng 13: 281-292.

30. Minuth WW, Denk L, Glashauser A (2010) A modular culture system for the generation of multiple specialized tissues. Biomaterials 31: 2945-2954.

31. Minuth WW, Denk L, Hu K (2007) The role of polyester interstitium and aldosterone during structural development of renal tubules in serum-free medium. Biomaterials 28: 4418-4428. 
Citation: Glashauser A, Denk L, Minuth WW (2011) Polyester Fleeces used as an Artificial Interstitium Influence the Spatial Growth of Regenerating Tubules. J Tissue Sci Eng 2:105. doi:10.4172/2157-7552.1000105

32. Roessger A, Denk L, Minuth WW (2009) Potential of stem/progenitor cell cultures within polyester fleeces to regenerate renal tubules. Biomaterials 30 : 3723-3732.

33. Minuth WW 1987 Neonatal rabbit kidney cortex in culture as tool for the study of collecting duct formation and nephron differentiation. Differentiation 36:12-22.

34. Hu M, Deng R, Schumacher KM, Kurisawa M, Ye H, et al. (2010). Hydrodynamic spinning of hydrogel fibers. Biomaterials 31: 863-9.

35. Weyhe D, Belyaev O, Buettner G, Mros K, Mueller C, et al. (2008) In vitro comparison of three different mesh constructions. ANZ J Surg 78: 55-60.

36. Kuwahara M, Shi LB, Marumo F, Verkman AS (1991) Transcellular water flow modulates water channel exocytosis and endocytosis in kidney collecting tubule. The J Clin Invest 88: 423-429.

37. Hamm-Alvarez SF, Sheetz MP (1998) Microtubule-dependent vesicle transport: modulation of channel and transporter activity in liver and kidney. Physiol Rev 78:1109-1129.

38. Yasmeen T, Yasmin F, Qureshi GS (2008) To evaluate the role of diclofenac sodium on renal parenchyma of young albino rats. Pak J Pharm Sci 21: 98-102.

39. Knepper MA, Danielson RA, Saidel GM, Post RS (1977) Quantitative analysis of renal medullary anatomy in rats and rabbits. Kidney Int 12: 313-323.

40. Cole BR, Brocklebank JT, Murray BN, Peterson LJ, Robson AM (1981) Maturation of the developing rabbit kidney: variations in cellular size and contents. Pediatr Res 15: 916-920.

41. Miess C, Glashauser A, Denk L, deVries U, Minuth WW (2010) The interface between generating renal tubules and a polyester fleece in comparison to the interstitium of the developing kidney. Ann Biomed Eng 38: 2197-2209.

42. Dankers PYW, Boomker JM, Meijer EW, Popa ER, van Luyn MJA (2011) From kidney development to drug delivery and tissue engineering strategies in renal regenerative medicine. J Control Release 152:177-85.

43. Vestweber D, Kemler R, Ekblom P (1985) Cell-adhesion molecule uvomorulin during kidney development. Dev Biology 112: 213-221.

44. Mah SP, Saueressig H, Goulding M, Kintner C, Dressler GR (2000) Kidney development in cadherin-6 mutants: delayed mesenchyme-to-epithelial conversion and loss of nephrons. Dev Biol 223: 38-53.

45. Dankers PY, Boomker JM, Huizinga-van der Vlag A, Wisse E, Appel WP, et al. (2011) Bioengineering of living renal membranes consisting of hierarchical, bioactive supramolecular meshes and human tubular cells. Biomaterials 32 723-33.

46. Lelongt B, Ronco P (2003) Role of extracellular matrix in kidney development and repair. Pediatr Nephrol 18: 731-742.

47. Lewis DJ, Prentice DE (1979) Ultrastructure of rhesus monkey renomedullary interstitial cells. Lab Animal 13:75-79.

48. Alcorn D, Maric C, McCausland J (1999) Development of the renal interstitium Pediatr Nephrol 13: 347-354
49. Sundelin B, Bohman SO (1990) Postnatal development of the interstitial tissue of the rat kidney. Anat Embryol (Berl) 182:307-317.

50. Kaissling B, Hegyi I, Loffing J, Le Hir M (1996) Morphology of interstitial cells in the healthy kidney. Anat Embryol (Berl) 193: 303-318.

51. Mcauliffe WG (1980) Histochemistry and ultrastructure of the interstitium of the renal papilla in rats with hereditary diabetes insipidus (Brattleboro strain). Am J Anat 157:17-26.

52. Takahashi-Iwanaga $H$ (1991) The three-dimensional cytoarchitecture of the interstitial tissue in the rat kidney. Cell Tissue Res 264: 269-281.

53. Kaissling B, Le Hir M (2008) The renal cortical interstitium: morphological and functional aspects. Histochem Cell Biol 130: 247-262.

54. Fujigaki Y, Muranaka Y, Sun D, Goto T, Zhou H, Sakakima M, et al. (2005) Transient myofibroblast differentiation of interstitial fibroblastic cells relevant to tubular dilatation in uranyl acetate-induced acute renal failure in rats. Virchows Arch 446:164-176

55. Minuth WW, Denk L, Blattmann A, Castrop H (2008) Collagen type III is an important linking molecule between generated renal tubules and an artificial polyester interstitium. J Clin Rehabil Tissue Eng Res 12: 6201-6208.

56. Minuth WW, Denk L, Meese C, Rachel R, Roessger A (2009) Ultrastructura insights in the interface between generated renal tubules and a polyester interstitium. Langmuir 25: 4621-4627.

57. Han HJ, Sigurdson WJ, Nickerson PA, Taub M (2004) Both mitogen activated protein kinase and the mammalian target of rapamycin modulate the development of functional renal proximal tubules in matrigel. J Cell Sci 117 : 1821-1833.

58. Kramann R, Couson SK, Neuss S, Kunter U, Bovi M, et al. (2011) Exposure to uremic serum induces a procalcific phenotype in human mesenchymal stem cells. Aterioscler Throm Vasc Biol PMID 21680902

59. Fleischmajer R, Jacobs L, Perlish JS, Katchen B, Schwartz E, Timpl R (1992) Immunochemical analysis of human kidney reticulin. Am J Pathol 140: 1225 1235

60. Douglas T, Heinemann S, Bierbaum S, Scharnweber D, Worch H (2006) Fibrillogenesis of collagen types I, II, and III with small leucine-rich proteoglycans decorin and biglycan. Biomacromolecules 7: 2388-2393.

61. Nagai Y, Miyata K, Sun G, Rahman M, Kimura S, et al. (2005) Aldosterone stimulates collagen gene expression and synthesis via activation of ERK1/2 in rat renal fibroblasts. Hypertension 46:1039-1045

62. Xu G, an Liu, Liu X (2008) Aldosterone induces collagen synthesis via activation of extracellular signal-regulated kinase 1 and 2 in renal proximal tubules. Nephrology (Carlton) 13: 694-701.

63. Diah S, Zhang G, Nagai Y, Zhang W, Gang L, et al. (2008) Aldosterone induces myofibroblastic transdifferentiation and collagen gene expression through the Rho-kinase dependent signaling pathway in rat mesangial cells. Exp Cell Res 314: 3654-3662.

64. Lemley KV, Kriz W (1991) Anatomy of the renal interstitium. Kidney Int 39: 370-381. 